\title{
ARE WE RE-MARGINALIZING DISTANCE EDUCATION STUDENTS AND TEACHERS?
}

\author{
Melody M. Thompson \\ The Pennsylvania State University
}

\begin{abstract}
Changes in the language we use to talk about our activities in service of this mission and a concomitant increased emphasis on blended learning are two trends that emphasize the importance retaining important meaning and knowledge associated with earlier practice and do not limit our thinking by unnecessarily circumscribed discourse. Educators should keep an intentional awareness of the "distance" inherent in the activities and a focus on the multidimensional nature of "education," which includes but is hardly coterminus with "learning."
\end{abstract}

\section{KEYWORDS}

Language, Distance Education, Blended Learning, Online Learning, E-Learning

\section{INTRODUCTION}

The Sloan-C mission is to make education "a part of everyday life, accessible and affordable for anyone, anywhere, at any time" and "to improve online education in learning effectiveness, access, affordability for learners and providers, and student and faculty satisfaction.” This paper explores possible effects of two trends on particular aspects of the experiences of students and faculty: 1) changes in the language we use to talk about our activities in service of this mission and 2) a concomitant increased emphasis on blended learning. The starting place for this exploration will be the four main Session 2 papers for the 2006 Sloan-C Invitational Summer Research Workshop. In highlighting specific issues in these papers, I will use the terminology the authors themselves employ to talk about our educational endeavors, that is, blended learning, online learning, and e-learning. Subsequently, however, I will offer an argument for the inadequacy-one might even go as far as to say the dangerous inadequacy-of these terms to appropriately describe and guide what the educational community does in these new teaching and learning environments.

\section{SELECTED ISSUES FROM THE FOUR PAPERS}

Dziuban, Moskal, and Futch offer an intriguing look at generational differences in student attitudes toward blended learning. They correctly note that "blended learning is a mental model that is evolving, rather than a well-defined pedagogical entity" [1]. This statement has a number of implications for students and teachers in blended programs, for our study of the elements of the phenomenon and, subsequently, for our ability to have an impact on how the model develops linguistically, conceptually, and pedagogically. The authors' emphasis on the metaphorical portrayal of reality is extremely important but may be overlooked or discounted by those who think of language only as a reflection of reality, rather than as both reflection and shaper. This point will be discussed at length below. Another implication to which I will return later is the connection between blended learning and access; these authors offer important insights into the psychological responses of students in blended learning courses and programs; yet what of those students who are not in the those courses, particularly those who reject the blended 
option because its on-campus component effectively cuts them off from access to these educational opportunities? A final area of shared interest is that of the faculty experience; I will focus particularly on issues of expertise and satisfaction in the discussion below.

Vignare's impressive review of the literature underlines Dziuban and colleagues' point about the stillambiguous nature of blended learning. Her vacillation between discussions of research on blended learning and that examining online learning illustrates some of the difficulties in trying to make definitive statements about the effectiveness of blended learning. There has been little research on the many manifestations of blended learning - with what has been done showing conflicting results_and at this point we don't know just how much of what we have learned about online education is applicable to the blended learning environment(s). Indeed, to the extent that the phenomenon matches its name, that is, becomes truly "blended," the face-to-face and online elements of the phenomenon will disappear into a new and different whole, making it difficult to identify the contribution of particular elements to effectiveness. The variable nature of the concept of effectiveness in both technology-supported and "traditional" face-to-face instruction intensifies the challenge of making sense of the research. These challenges lead to somewhat questionable conclusions in both papers, such as the idea that blended learning is the "best of the classroom and the best of online learning" [1] or that it should be implemented because it is easier to get institutions to adopt blended learning than it is to get them to adopt approaches that research suggests are more effective, but too "dramatic," for slow-to-change institutions to adopt [2]. Vignare raises the key issue of access when she notes that "requiring online learning for students who lack internet access is problematic" [2]; what she does not address is the at least equally problematic requirement that students in blended courses and programs take some portions of classes and programs on campus. Implications of this characteristic of blended programs will be discussed below.

Garrison [3] focuses his attention on the online community of inquiry (CoI). The specific connection to the ideas that I would like to develop is through the concept of teaching presence. Interestingly, a focus on teachers first appears in Garrison's discussion of cognitive presence, where he quotes Meyer as suggesting that "Faculty need to be more directive in their assignments", and then goes on to note that "others have also speculated that the role of the instructor is a major factor" in the progressive development and resolution of inquiry. Garrison further underlines the level of expertise necessary for faculty to provide appropriate input and direction, describing the necessary skills as "crucial," "delicate," and "challenging." Moving into the actual discussion of teaching presence, Garrison again underlines the importance of faculty: "The body of evidence is growing rapidly attesting to the importance of teaching presence for successful online learning.... The consensus is that teaching presence is a significant determinate of student satisfaction, perceived learning, and sense of community" [3]. The intent of my focus here on the importance of teachers and teaching behaviors will, I hope, become clear below.

Finally, Arbaugh's paper [4] offers results of a study that examined the idea that the three CoI elementssocial, teaching, and cognitive presence-exist distinctively in e-learning environments. Again, my interest is specifically on Arbaugh's view of the faculty experience. With Garrison, he notes "the importance of instructor behaviors" and makes the interesting comment that past attempts to operationalize and measure the concept of teaching presence may actually have been focused on "teacher presence", as opposed to teaching presence, which in earlier conceptualizations was understood to be exhibited by both teachers and students. This distinction, Arbaugh suggests, may "reflect the reality of the online environment” [4]. Some implications of this view will be discussed below.

In the next part of the paper I will discuss the importance of the language we use to talk about our educational practice. Both what we say and what we don't say have a profound impact in shaping individual practice, institutional policies, and research agendas. Specifically I argue that the current "terms of art" serve to limit our conceptualization of our practice, as well as potentially to marginalize certain students and faculty members. Portions of the following section will appear in a slightly different 
form in the chapter "From distance education to e-learning" in the forthcoming Handbook of E-learning Research [5].

\section{THE POWER OF LANGUAGE}

Linguistic theory and research suggest that language is a social process that both reflects reality and dynamically contributes to the construction of reality: "it is necessary to examine not only the social determination of language use but also the linguistic determination of society" [6]. This latter idea, the linguistic determination of society, has particular relevance as we discuss the aspect of society comprising professional educators.

Issues of language are central to understanding any work community or profession. Language, particularly in the form of texts, dynamically creates and maintains a particular profession by first structuring human activity within it to shape initial visions of professional reality and then by shaping the subsequent actions of individuals within that community [7]. Such shaping takes place through a variety of textual channels including institutional policy documents and professional newsletters, journals, and conferences.

Together these discourse channels work to influence judgments about research agendas, prioritization of institutional support, and the decision-making process as it relates to institutional change. Linguistic conventions that make it more or less difficult to conceive of or communicate about certain ideas either expand or limit a profession's views of reality both in terms of what is, as well as what could be and should be $[7,8]$. For this reason we need to ensure that our communications about what we do not only reflect the reality of our practice, but also enable and encourage its robust development in ways that maximize the benefits to all participants.

\section{DISTANCE EDUCATION AND ITS TERMINOLOGY}

According to Anderson and Elloumi [9], during the last 150 years distance education has "evolved" through four generations: 1) correspondence study, 2) those approaches characterized by the mass media (television and radio), 3) synchronous technologies (video- and audio-conferencing), and 4) computer conferencing. They further suggest the emergence of a fifth generation, "the educational Semantic Web." Each new generation has been added to the preceding ones, with the result that all five are now operating concurrently in the overall educational context.

In the first three generations, distance education was a relatively minor, often marginalized, activity conducted and studied by a small group of educators dedicated to broadening access to educational programming to un-served or under-served populations of students. These educators employed a variety of media and media combinations to offer programs to students who were unable to participate in educational programs at traditional institutions. Traditional colleges and universities generally viewed such efforts as ancillary to their core institutional mission, and the limited support they provided focused on ensuring that such programs did not detract from the institution's reputation. [10].

Then, largely as a result of the power and reach of the World Wide Web, distance education was "discovered" by higher education. Recast first as online learning, then as e-learning, and finally as blended learning, it has moved from the margins into the mainstream. No longer is it an alternative primarily for non-traditional students; indeed, it is rapidly being incorporated into programs serving traditional campus-based students [10]. This rapid movement into the mainstream of higher education reflects a new image for distance education. Indeed, the "The E Is For Everything" promise [11] is a technology-based transformation of most if not all aspects of society, including education. Yet there is a 
seemingly minor catch necessary to "lock in" this success: distance education must adopt a more current terminology. The term "distance education"-perceived as outdated by some, unknown to others, and suspect to others still—must be changed to something more relevant, to something that "sells": online learning, e-learning, or blended learning.

\section{FROM THE MARGINS TO THE MAINSTREAM...AND BACK?}

Even as distance education began to achieve long-deferred recognition for the benefits it has provided and continues to provide, this established field of practice and research was almost immediately threatened with re-marginalization. This threat has taken the form of an ahistorical attitude reflected in 1) the almost universal rejection of the term "distance education" in favor of new terms coined to describe a type of education characterized not by "distance" - a field of little interest to all but a few people - but rather by the term "electronic" (shortened to "e"), which was of great interest to most people, and 2) the failure of e-learning researchers to build on earlier theories and studies of prior forms of distance delivery.

It is the first point, above, that I will develop in this paper. Specifically I am asking: What are the implications of this change in terminology, particularly for students and faculty?

A variety of reasons have been offered for rejecting the term "distance education.” Some have suggested that the term has associations with a marginalized activity, particularly correspondence study. Others note that many "online learners" are physically present on campuses rather than at a distance. Still others believe that "distance" refers to a physical positioning characterized by institutions and teachers at the center, making the term "distance education" inappropriate for the widely prescribed "learner-centered" experience.

This change in terminology is probably a foregone conclusion, in spite of efforts by some distance educators to forestall it $[12,13,14]$. Yet I believe that the reasons for change presented above have at best only partial validity, and that substitution of new terms, while solving some difficulties, introduces others. For this reason I would like to present an argument, if not for retaining the term distance education, at least for recognizing the crucial nature of both elements of the term and for incorporating a focus on both "distance" and "education" in developing theories, practice, and research of online and blended learning.

\section{A. Distance Is Not Dead}

Rumors relating to the "death of distance" [15] are reminiscent of Mark Twain's statement that rumors of his death had been greatly exaggerated. Merely stating that distance is dead does not make it so. The "distance" in distance education has been assumed by many outside the field and new to the practice of online education as referring to a straightforward physical property: the physical space separating learners from institution, teacher, and each other. Given this understanding of distance, some educators have suggested a need to "update" terminology. Since physical distance can be effectively bridged by new information and communications technologies, keeping distance as the defining characteristic of teaching and learning supported by such technologies is no longer appropriate.

This line of thinking has several weaknesses. First, if one physical property is inadequate for defining a particular activity, simply replacing the property of distance with another physical property- "online," "electronic" (shortened to "e"), "blended," etc.-is both conceptually confusing and at least equally inadequate for defining the phenomenon [14]. "Online," which originally referred to actual connection to a physical line, provides little conceptual or definitional guidance when connections may be maintained by physical "lines" but just as often are supported by wireless means. Similarly, the "e" in e-learning stands for electronic, an appropriate designation for a wide range of technologies, although it is used almost always to refer to computer networks. And "blended" can refer to the mixing of a number of 
elements: e-learning with traditional learning, online learning with face-to-face, different media, different contexts, different learning theories, different learning objectives, and different pedagogies [16]. These terminological shortcomings have led Saba [14] to conclude that none of the terms currently proposed to replace distance education offer a valid descriptive, explanatory, or organizing construct.

Second, distance educators never viewed themselves as working to bridge a merely physical distance. Rather, their conceptualization of their teaching-learning environment reflected a social science perspective that recognized "distance" as a factor that strongly influences all interpersonal interactions, including that known as "education" [14]. For distance educators, "distance" has always referred to both a physical space that needs to be bridged and, even more importantly, the psychological distance that characterizes any educational activity, whether blended, online, or face-to-face [17, 18]. Peters, for example, notes that "pedagogic distance" can be present whether the instructor is separated from the student or is located in the same room, as in a large lecture class [16]. In Learning to Listen, Learning to Teach, Jane Vella, writing about face-to-face adult education, suggests that "a significant issue when educating adults is the perceived distance between teacher and students" and finding dialogic ways to close this distance [19]. Saba reinforces this idea with his observation that

[Physical] separation can be bridged by communication technology, a fact demonstrated by teachers and students everywhere. But if students and teachers are separated by the total absence of dialog, as occurs in many classrooms across the country and around the world, bringing them together until they stand nose to nose will not offer a solution [13].

Clearly, the concept of distance is relevant to both technologically mediated and face-to-face education. To underestimate the relevance to either environment suggests a fundamental lack understanding of a universal educational challenge.

\section{B. Education vs. Learning}

The term "education" is also out of favor with proponents of up-to-date terminology. Perceptions that teaching-learning environments have in the past focused too narrowly on the instructor or the institution rather than on the student prompted educators to coin new terms intended-remember the power of language - to refocus attention on the students, who are simultaneously renamed "learners." This change is terminology, although well-intentioned, effectively eliminates one half of the social interaction formerly referred to as education. Whereas education is a multifaceted activity understood to involve a variety of players and activities - teachers and teaching, students and studying, information, knowledge and, it is hoped, learning - online learning, e-learning, and blended learning are terms comprising one word or letter representing a physical property of technology and the hoped-for outcome (learning) for one participant in the interaction.

The substitution of "learning" for "education" is one response to the call to "democratize" education by empowering students or learners. Yet it also has the feel of magical thinking about it: Name the promise (learning) and it's yours. This attitude is a natural outgrowth of our attitude toward technology and its perceived ability to deliver a variety of astonishing results completely divorced from any need to understand how and why it works. However, an attitude that is relatively harmless in relation to our DVD players and iPods becomes more problematic when we begin to use such shorthand thinking for complex social systems such as education. Does shorthand terminology lead to shorthand thinking? I believe it has in the case of online learning, e-learning, and blended learning.

\section{Re-marginalizing Distant Students}

Things that are not named (whether through spoken word, text, or images) are commonly devalued or ignored. This result is a function of the "exclusionary power" of language [20]. Belief in this dynamic is 
reflected in society's efforts over the last several decades to more equitably represent women and minorities in a variety of textual and visual contexts. Similarly, we must carefully consider how we name educational activities and how we communicate about them if we want to maximize their effectiveness and ensure that their value is recognized practically through institutional resource, planning, and research decisions. Differences in terminology are not mere hairsplitting distinctions; they have very real and potentially profound implications for excluding important aspects from our thinking about higher education. Specifically, unless care is taken to forestall this result, our terminology may contribute to the re-marginalization of both true distant students (e.g., those who can never attend a physical campus) and those who teach in these new environments.

Motivated by a desire to increase institutional enrolments with students outside their traditional service areas [21], many institutions in the last decade became interested in Web-based education. These institutions quickly learned what distance education providers had long known: Distant students have unique needs related to physical and psychological separation, and the cost of providing appropriate services to bridge that distance is high. At the same time, the higher education community was becoming aware that its "traditional" resident students were no longer traditional in either their characteristics or expectations. Faced with both the unforeseen costs of serving distant students and the technological expectations of "a generation hardwired since birth...[and] impatient with a lack of technological sophistication in others" [22], many institutions pulled back from plans to expand delivery to new populations and decided instead to incorporate the concept of e-learning into the traditional educational environment via blended programs. Blended programs promise no focus on distant students; indeed, in many cases institutions view these programs as a way to re-vitalize, in some cases even transform, traditional campus-based teaching and learning. This is indeed a benefit that we should not undervalue, particularly in that it not only enhances the educational experience of traditional students but also truly increases access for some students: those who have the flexibility to pursue a portion, but not all, of their studies on a physical campus. However, because resources initially planned to support extension of programs to distant students are now in many cases being used to strengthen campus-based education, this shift gives renewed credence to charges that technology-based education, rather than decreasing the gap between the educational "haves" and "have-not," gives more educational capital to those who already have it [23, 24].

\section{The Invisible Teacher}

A major determinant in the ultimate success of technology-based higher education programs will be a strong faculty commitment to teaching in this new environment. Many faculty members have voluntarily embraced these new approaches and have reported benefits that make the new educational environment a satisfying addition or alternative to traditional face-to-face instruction [25, 26, 27, 28].

However, the fact that some faculty members (erroneously labeled "early adopters" based on a misapplication of Everett Rogers' diffusion of innovations theory) have embraced technology-based education is not necessarily evidence of the gradual but ultimately universal adoption by all faculty members [29]. Many others have signaled resistance to participating, and much of the resistance seems to be grounded in concern about the ability of these new approaches to provide the personal and professional satisfaction people naturally seek in their vocations. Such concerns make the linguistic invisibility of the teaching function in the terms online learning, e-learning, and blended learning particularly problematic.

Those who teach in higher education are more than service providers or content experts; they are professionals who seek personal as well as professional satisfaction from their chosen fields. Student needs related to networked teaching-learning environments are discussed frequently in publications and institutional policy deliberations; however, the equally legitimate personal needs and motivations of faculty are often lost in today’s “learner-centered” rhetoric. The 2000 American Faculty Poll reported 
that, for higher education faculty, "one of the most important factors...in their decision to pursue an academic career was the enjoyment of working with students" [30]. Other research has shown that satisfaction with teaching in the online environment is directly related to the extent to which it allows faculty members to attain this and other personal rewards, including "self-gratification," and "overall job satisfaction” [31].

Unfortunately, much of the recent discourse has in effect relegated teachers to a minor role. Naming what they do as some form of "learning" obscures their professional contribution (i.e. teaching or educating). Equally disheartening to many faculty members are calls for their "disaggregation" and for "training" in the skills they need and the tasks they must perform; such terminology essentially de-professionalizes faculty. As a participant in one research study on faculty satisfaction noted, "this change in the pattern of my working day...has reduced and decentered intellectual tasks to competency and generic skill” [32]. Jaffee [33] suggests that this type of faculty dissatisfaction results from a fundamental challenge to one's core professional identity, a challenge exacerbated by the shift in power relations resulting from a perceived need on the part of institutions to exercise more-than-usual administrative control over this academic endeavor in order to justify and "protect" institutional investments. As Shedletsky and Aitken [34] observe, "Although administrators may have no expertise in computer pedagogy, scholarship, or general computer operation, administrators often make decisions on behalf of faculty." Faculty success subsequently becomes more and more dependent on factors outside of their control. This generalized shift in power relations often leads to other changes that leave many faculty members feeling that their roles have been de-professionalized, including:

- required training workshops in which faculty are made to feel incompetent or ignorant by "impatient, patronizing, or insolent support staff;"

- assumption of ownership by the institution of faculty members' online courses; and

- lack of recognition for e-learning work within the institutional reward structure [34].

bell hooks [35], writing about face-to-face higher education, quotes Thich Nhat Hanh's statement that "the practice of a...teacher or any helping professional should be directed toward his or herself first, because if the helper is unhappy, he or she cannot help many people." hooks adds that "it is rare...to hear anyone suggest that teachers have any responsibility to be self-actualized." Rather than "the objectification of the teacher" that seems to "denigrate notions of wholeness" [35], our terminology, practice, and research should reflect a holistic approach to learning and teaching that stresses both learner and teacher self-actualization. In conceptualizing, labeling, and communicating about online teaching and learning we should keep teachers as well as students at the center of a process aimed at fostering the personal growth of all participants. Otherwise, we may perpetuate the ambivalence many higher education faculty members express about participating in this new form of education [36].

\section{BACK TO THE FOUR PAPERS}

In this section I will try to make explicit the connections between the issues from the four papers I identified in the first section of my paper and my subsequent arguments. I believe that seeing these connections and responding to them is crucial if we hope to realize the Sloan-C vision through appropriately focused research and practice.

The first issue has to do with the power of language to shape our thinking and subsequently guide our research and practice. Of the four sets of authors, Dziuban, Moskal, and Futch explicitly note the importance of linguistic issues in our communication with each other, yet I believe their own rhetoric operates against one of their stated goals: a "less constraining” language [1]. Dziuban and colleagues, Vignare, Garrison, and Arbaugh all agree on the crucial nature of the faculty function, yet all four papers - reflecting almost universal current usage-use terminology that leaves that function un-named: 
online learning, e-learning, blended learning. Not only is this language more constraining since it leaves out a crucial function in the educational process, but it also has the potential to contribute to a de-valuing of that function since naming confers value and attention. This result is already apparent in institutional attitudes and actions that de-professionalize faculty, with resultant negative impact on faculty satisfaction. If, indeed, the "reality of the online environment" [4] shows that the teaching function is "crucial," that "instruction is at the heart" [2] of online and blended learning, why are teachers and teaching so obviously absent from the terms we apply to these activities? In my own writing I try where possible to minimize these limitations through the use of what is admittedly not ideal, but is hopefully "less constraining," terminology, such as technology-based education, online education, and online teaching and learning. Yet even given an intentional effort I sometimes find myself constrained by others' requirements, such as prescribed titles or editorial policy.

Both the new terminology and my own inadequate substitutions fail to address the other limitation above: the fact that rejection of the term "distance education" also obscures a key educational challengedistance-and instead focuses attention in a linguistically muddled way on physical characteristics of delivery systems (online, electronic, blended). Psychological and pedagogical distances are very real threats to success in all educational environments. By failing to name the challenge are we decreasing the chances that appropriate attention is given to it in research and practice? Given the popular acceptance of the new terminology, it is unlikely that, as Saba proposes, "distance education" will not only be reinstated as the preferred term, but will become the all-encompassing term of art for both traditional and technology-based education [13]. However, as we move forward under the banners of the new terminology to improve practice, develop policy, and determine research agendas, let us make sure that we remember the distance that inevitably separates stakeholders in our activities.

The persistence of distance as a challenge connects to the second issue I would like to highlight, that of access. This issue is made explicit in Vignare's and Dziuban, Moskal, and Futch's papers [2, 1] on blended learning. Both papers suggest that blended learning increases access to educational opportunities for students, and Vignare specifically mentions increased access for disabled students. However, neither paper addresses the other side of the coin: the limitations on access imposed by hybrid courses' or blended programs' requirement for some level of campus attendance. Dziuban and colleagues offer important insights into the attitudes and psychological responses of students in blended programs, with their focus intentionally limited to the students whose initial attitude was positive enough to motivate them to enroll in these courses. However, there is another population of students who will never present themselves for us to study: those whose situations preclude any attendance on campus. For these students, both able-bodied and disabled, blended programs close off access to educational opportunities as completely as do traditional programs. Given the increasing proportion of adult students in higher education, it is important to realize that blended programs are not the best of both worlds for many students facing a variety of situational barriers; re-channeling resources from distance programs to blended programs, while better serving some shuts out others, thereby limiting achievement of the SloanC mission.

\section{CONCLUSION}

The practices currently referred to as online learning, e-learning, and blended learning are the most recent iterations of a field of practice with a long tradition of theory building, research, and practice. Change in terminology is an inevitable aspect of social change; however, we need to ensure that in making such changes we neither lose important meaning and knowledge associated with earlier practice nor limit our thinking by unnecessarily circumscribed discourse.

To develop and support a robust understanding of the educational activities discussed here we need to maintain 1) an intentional awareness of the "distance" inherent in the activities and 2) a focus on the 
multidimensional nature of "education," which includes but is hardly co-terminus with "learning." Our ability to achieve the Sloan-C mission through research and improved practice will be enhanced to the extent that we maintain a focus on all of the essential elements of these activities.

\section{ABOUT THE AUTHOR}

Melody M. Thompson is Assistant Professor of Education and Coordinator of Doctoral Studies in The Pennsylvania State University Adult Education Program. In that role she teaches and advises masters' and doctoral students, with much of her teaching being done online through the World Campus. Her primary research interests are faculty satisfaction and the institutional policy environment for online learning, as well as diversity issues in adult education. Dr. Thompson received her bachelor's degree in English from Bryn Mawr College and both her M.Ed. and D.Ed. from Penn State. Her past positions include Director of Planning and Research for the World Campus, Director of the American Center for the Study of Distance Education (ACSDE), and Sloan-C Editor for effective practices in faculty satisfaction. Dr. Thompson is the author of numerous articles and book chapters, as well as co-author of the McGraw-Hill Handbook of Distance Learning.

\section{REFERENCES}

1. Dziuban, C., P. Moskal and L. Futch. Student Satisfaction with Asynchronous Learning. Journal of Asynchronous Learning Networks 11(1): April 2007.

2. Vignare, K. Review of literature on blended learning: Using ALN to change the classroom-Will it work? Paper for the Sloan-C Summer Invitational Workshop, Baltimore, MD, August 2006.

3. Garrison, D. R. Online community of inquiry review: Social, cognitive, and teaching presence issues. Journal of Asynchronous Learning Networks 11(1): April 2007.

4. Arbaugh, B. An empirical verification of the Community of Inquiry framework. Journal of Asynchronous Learning Networks 11(1): April 2007.

5. Thompson, M. M. From distance education to e-learning. Handbook of E-learning Research, London: Sage, (in press for August 2007).

6. Fairclough, N. Language and Power. New York: Longman, 1989.

7. Bazerman, C. and J. Paradis. Textual Dynamics of the Professions. Madison, WI: University of Wisconsin Press, 1990.

8. Thompson, M. M. An historical and linguistic analysis of women in the histories and the early literature of adult education, 1926-1962: Toward a balanced historiography of the field. Doctoral dissertation, The Pennsylvania State University, 1996.

9. Anderson, T. and F. Elloumi. Introduction. In: T. Anderson and F. Elloumi (Eds.), Theory and Practice of Online Learning, xiii-xxii. Athabasca, Canada: Athabasca University, 2004. http://www.cde.athabascau.ca/online_book.

10. Thompson, M. M. and M. Irele. Evaluating distance education programs. In: M. Moore, and W. Anderson (Eds.), Handbook of Distance Education, 567-584. Mahwah, NJ: Lawrence Erlbaum, 2003.

11. Katz, R. and D. Ohlinger. The " $E$ " is for Everything. San Franciso: Jossey-Bass, 2000.

12. Kanuka, H. and D. Conrad. The name of the game: Why "distance education” says it all. Quarterly Review of Distance Education 4(4): 385-393, 2003.

13. Saba, F. Distance education theory, methodology, and epistemology: A pragmatic paradigm. In: M. Moore and W. Anderson (Eds.), Handbook of Distance Education, 3-20. Mahwah, NJ: Lawrence Erlbaum, 2003.

14. Saba, F. Is distance education losing its identity? Or what should our field be called these days? Presentation at the $20^{\text {th }}$ Annual Conference on Distance Teaching and Learning, Madison, WI, August 3-5, 2005. 
15. Cairncross, F. The Death of Distance: How the Communications Revolution Will Change Our Lives. Boston: Harvard Business School Press, 1997.

16. Oliver, M. and K. Trigwell. Can 'blended learning' be redeemed? E-Learning 2(1): 17-26, 2005.

17. Moore, M. G. The individual adult learner. In: M. Tight (Ed.), Adult Learning and Education, 153168. London: Croom Helm, 1983.

18. Saba, F. and R. L. Shearer. Verifying key theoretical concepts in a dynamic model of distance education. American Journal of Distance Education 8(1): 36-59, 1994. Retrieved May 4, 2006 from ERIC Database.

19. Vella, J. Learning to Listen, Learning to Teach: The Power of Dialogue in Educating Adults. San Francisco: Jossey-Bass, 2002.

20. Porter, J. Intertextuality and the discourse community. Rhetoric Review 5(1): 38-39, 1986.

21. National Center for Education Statistics. Distance education at degree-granting postsecondary institutions: 2000-2001. Washington, DC: US Department of Education, 2003. http://nces.ed.gov /pubsearch/pubsinfo.asp?pubid=2003017.

22. Taylor, M. L. Generation NeXt comes to college: 2006 updates and emerging issues. 2006. http://www.taylorprograms.org/images/Gen_NeXt_article_HLC_06.pdf.

23. Bates, A. Cultural and ethical issues in international distance education. Paper presented at the Engaging Partnerships: Collaboration and Partnership in Distance Education UBC/CREAD Conference, Vancouver, Canada, September 21-23, 1999. http://bates.cstudies.ubc.ca/pdf /CREAD.pdf.

24. Tait, A. The convergence of distance and conventional education. Some implications for policy. In: A. Tait and R. Mills (Eds.), The Convergence of Distance \& Traditional Education, 141-160. New York: Routledge, 1999.

25. Frederickson, E., A. Pickett, K. Swan, W. Pelz and P. Shea. Factors influencing faculty satisfaction with asynchronous teaching and learning in the SUNY learning network. Online Education, Vol. 1: Learning Effectiveness and Faculty Satisfaction, Needham, MA: Sloan-C, 1999.

26. Hartman, J. and B. Truman-Davis. Factors relating to the satisfaction of faculty teaching online courses at the University of Central Florida. Online Education, Vol. 2: Learning Effectiveness, Faculty Satisfaction, and Cost Effectiveness, 109-128. Needham, MA: Sloan-C, 2001.

27. National Education Association. A Survey of Traditional and Distance Learning Higher Education Members. Washington: NEA, 2000.

28. Thompson, M. Faculty satisfaction in Penn State's World Campus. Online Education, Vol. 2: Learning Effectiveness, Faculty Satisfaction, and Cost Effectiveness, 129-144. Needham, MA: SloanC, 2001.

29. deJager, P. The danger of the “early adopter" myth. 2005. http://technobility.com/docs article032.htm.

30. Bower, B. Distance Education: Facing the faculty challenge. Online Journal of Distance Learning Administration 4(2): Summer 2001. http://www.westga.edu/ distance/ojdla/summer42/bower42.htm.

31. Schifter, C. Perception Differences about Participating in Distance Education. Online Journal of Distance Learning Administration 5(1): 2002.

32. Brabazon, T. Internet teaching and the administration of knowledge. First Monday 6(6): 2001. http://firstmonday.dk/issues/issue6_6/brabazkon/index.html.

33. Jaffee, D. Institutionalized resistance to asynchronous learning networks. Journal of Asynchronous Learning Networks 2(2): 1998. http://www.sloan-c.org/publications/jaln/v2n2/v2n2_jaffee.asp.

34. Shedletsky, L. J. and J. E. Aitken. The paradoxes of online academic work. Communication Education 50(3): 206-17, 2001.

35. hooks, b. Teaching to Transgress. Education as the Practice of Freedom. New York: Routledge, 1994.

36. Thompson, M. M. Faculty satisfaction in the online environment. In: J. R. Bourne and J. Moore (Eds.), Elements of Quality Online Education: Practice and Direction, 189-212. Needham, MA: Sloan-C, 2003. 